ISSN: 2716-1277

e-ISSN: 2716-1269

Available online at TIC https://jlic.iain-jember.ac.id/
Journal of Language Intelligence and Culture

Fakultas Tarbiyah dan Ilmu Keguruan

IAIN Jember

Vol. 2, No.1, Page 16-27, June 2020

\title{
Writing Strategies Used by Indonesian EFL Undergraduate Students across Their Proficiency and Gender
}

Istiqamah Ardila,

STAI Rasyidiyah Khalidiyah Amuntai ardilaistiqamah@gmail.com

\begin{abstract}
ARTICLE INFO
Article History:

Accepted: March 2020.

Approved: May 2020.

Published: June 2020

Key Words:

Writing strategies, EFL undergraduate students, Proficiency, Gender
\end{abstract}

DOI: $10.35719 / j l i c . v 2 i 1.20$

\begin{abstract}
Proficient writers in L2 setting used many kinds of strategies to face their difficulties in English writing. This study investigates the writing strategies used by Indonesian EFL undergraduate students and examines if there is any differences between proficient and less proficient students across their gender in choosing strategies in writing. The subject of the study consisted of 100 (one hundred) undergraduate students of English Department in Islamic State University of Antasari, Banjarmasin. A questionnaire was adopted from Peñuelas (2012) to gather data about student writing strategies. The categorization of proficient and less proficient of the students was based on the result of writing test. The results indicated that Indonesian EFL undergraduate students used six categories of writing strategies and compensation strategies was the most frequently used followed by affective strategies as the least frequently used. Proficient and less proficient students employed compensation strategies as the dominant strategies both male and female students. The differences of strategies used based on students gender did not occur in proficient students. However, the differences was significant of less proficient male and female students only in affective strategies while the rest was not significant. Furthermore, proficient female students used more strategies than male in term of categories while less proficient male used more strategies in memory and compensation strategies than female.
\end{abstract}

\section{INTRODUCTION}

Writing strategies is one of the learning strategies that employed by undergraduate students to help them improve and solve any problems during writing processes so that their writing meets college standards. Since writing in higher education is 
assumed to be a competence which enable students to communicate their knowledge and understanding in virtually any context (Lea \& Stierer, 200o), undergraduate students have to master it beside another skills (listening, speaking, and reading) to become a professional English teacher in EFL settings.

Strategies mean the specific actions, behaviors, or techniques that students use to improve their progress in developing second language skills (Oxford, 2003). It also can be said as considered actions to select and control by students to achieve their goal in learning (Winarto, 2002). Therefore, writing strategies can be define as selective techniques or actions used by students to improve their writing and achieve their goal in writing.

Students actually have personal strategies to overcome their problems during writing processes (Arifin, 2017). For instance, they started by brainstorming ideas through books or articles after they understood the demand of writing task. After that, they will read and reread again what they have written. They also considered how to connect their ideas to the other ideas in order to produce good quality in writing.

Writing in L2 is not easy for EFL undergraduate students. L2 writing process is strategically, rhetorically, linguistically different from first language (L1) writing process (Silva, 1993). Wang \& Weng (2002) said that L2 writing is a complex process of discovery which involves planning, reading/rereading the text, revision, and final editing as L2 writers have more than one language at their disposal. Culture also impact L2 writing as well as the genre of the writing task, cognitive development and interlanguage development $(\mathrm{Mu} \&$ Carrington, 2007). Therefore, the use of appropriate strategies is necessity for helping undergraduate students in English department make a good writing.

Recently, studies conducted by Chen (2011), Maarof \& Murat (2013), Mohite (2014), and Arifin (2017) revealed that students both in school and university in any level used various kinds of writing strategies to achieve their goal in writing in the terms of writing process or six writing strategies proposed by Oxford. Then, 


\section{JLIC}

proficient writers done many revision steps (Qamariah, 2016) and applied more strategies (Arifin, 2017) than compared to less proficient writers. In addition, proficient writers mostly used reading and rereading strategies for several purposes such as revising and editing the text, developing ideas, and getting new ideas (Arifin, 2017).

Moreover, Umamah \& Hidayanti (2018) and investigated the different writing strategies across gender involved undergraduate students by using Posteriori Taxonomy of Strategies of Learning English Writing Skill adopted from Mistar, Zuhairi, and Parlindungan (2014). They indicates that female had good and arranged planning before writing, read many articles to gain ideas, think carefully about mechanic in writing and tend to have more communication with others. In opposite, male students tried to fell relax when they are afraid of making mistakes in writing. Male students jot down some new words and make up some note before writing while female students started by good and arranged planning before producing an English text.

By using Oxford language learning strategies Sarab \& Farsani (2014) and Maharani, Fauziati, \& Supriadi (2018) conducted research in L2 setting related to undergraduate writing strategies. Sarab \& Farsani (2014) found that Iranian EFL learners employed metacognitive and cognitive strategies as the frequent strategies used while Maharani et al (2018) found that male students mostly used memory strategy and female students mostly used metacognitive strategy.

Previous studies above showed that students tended to use all strategies in their writing. The choice of strategies are influenced by several factor such as their proficiency in writing and gender. Aslan (2009) stated that psychological type, motivation, natiality, and gender as factors influencing strategy used. Students who have good ability in writing will use more strategies than less writing ability students. According to Bruning (in Peunelas, 2012) proficient writer have several common characteristics: (1) they organize information more efficiently by chunking information into larger 
units, (2) they are faster than novice writers at processing information because they search and represent problems more efficiently, (3) they have thoughts and actions that are highly automatized, (4) they pay more attention to the underlying nature of a problem rather than to superficial matters, (5) they spend more time analyzing the problem, (6) they break problems into subproblems and (7) they are better monitors within their domain of expertise.

Based on the review above, the researcher is interested in identifying writing strategies used by undergraduate student and examining differences in the strategies used between proficient students and less proficient students across their gender since the previous studies only compare the strategies between the proficient and less proficient writers. More specifically, the study investigates the following questions:

(a) What are writing strategies used by Indonesian preservice English teachers of State University of Islam?

(b) Is there any significant differences between writing strategies used by proficient male students to those used by proficient female counterparts?

(c) Is there any significant differences between writing strategies used by less proficient male students to those used by less proficient female counterparts?

\section{METHODS}

This study is intended to investigate which strategies mostly used by Indonesian EFL undergraduate students in writing. A quantitative surveys is conducted using descriptive methods with questionnaire as the main data of the study. 100 undergraduate students from English Department of Islamic State University of Antasari, Banjarmasin utilized as the sample of this study. A 47item 5 point Likert scale questionnaire on writing strategy use was adapted from Peñuelas (2012). It was developed on the basis of the subvaribales or subcategories of strategies by Oxford (1990) with each strategy type tapping into the students' use of memory, 


\section{JLIC}

cognitive, compensation, metacognitive, social, and affective strategies in writing. The writing strategies questionnaire was piloted and the Cronbach alpha coefficient was 0.85 which means that the reliability was highly reliable.

\section{RESULTS AND DISCUSSION}

Strategies Used

The finding showed that all participants use six strategies in writing. Three commonly strategies used by them are compensation strategies $(M=3.66)$, memory strategies $(M=3.36)$, and social strategies $(M=3.34)$ followed by metacognitive strategies $(M=$ 3.30), cognitive strategies $(M=3.23)$ and affective strategies $(M=$ 3.20). It can be seen that the mean score of each category is not too different. This indicates that they used all strategies in balance.

Table 1. The Means and Standard Deviations of Writing Strategies $(\mathrm{N}=100)$

\begin{tabular}{lccc}
\hline Writing Strategies & N & Mean & SD \\
\hline Memory Strategy & 100 & $3 \cdot 36$ & .58 \\
Cognitive Strategy & 100 & 3.23 & .39 \\
Compensation Strategy & 100 & 3.66 & .64 \\
Metacognitive Strategy & 100 & 3.30 & .48 \\
Affective Strategy & 100 & 3.20 & .59 \\
Social Strategy & 100 & 3.34 & .68 \\
\hline
\end{tabular}

Compensation strategies became the most frequently strategies used by undergraduate students. This indicates that students still have limited knowledge in English as L2. This kind of strategies allows students to use the new language for comprehension or production due to limited knowledge and they are used to make up for "an inadequate repertoire of grammar and vocabulary" (Oxford in Shi, 2017). As Oxford (2003) stated that compensation strategies help students make up for missing knowledge and significantly related to L2 proficiency in their study of native-English-speaking learners of foreign languages. In 
addition, memory strategies and social strategies has near mean score which is 3.36 and 3.34. It only has 0.02 difference in the value. Thus, it seems that the two strategies has equal score.

Memory strategies help learners store and retrieve new information while social strategies help them work with others and understand the target culture as well as the language. The three top strategies that mostly employed by students indicates that they more used direct strategies than indirect strategies to help them in writing task. Direct strategies involve direct learning and require mental processing of the language. (Oxford in Shi, 2017). Memory, cognitive, and compensation strategies are belong to direct strategies. On the other hand, although indirect strategies (metacognitive, affective, and social strategies) are not involved directly to the learning but it power the learning process.

Strategies Used by Proficient Male and Female Students in Writing

As Table 2 shows that proficient writers both male and female students mostly used compensation strategy $(M=3.75)$ followed by metacognitive strategies $(\mathrm{M}=3.40)$. Then, social and memory strategies had almost equal average is 3.37 and 3.36 , respectively. The same is true of the two lowest mean which are affective and cognitive strategies $(M=3.27$ and $M=3.26)$. The score was almost in the same level. It can be said that proficient students used all of the strategies in balance to solve any problems that occurs when they conducted a writing. As previous mentioned, metacognitive and social strategies are categorized into indirect strategies. Indirect strategies support learning indirectly but are powerful to learning process (Shi, 2017). This finding indicates that proficient students in writing use direct and indirect strategies to keep the quality of their writing. 


\section{JLIC}

Table 2. The writing strategies used by proficient writers.

\begin{tabular}{lccc}
\hline Writing Strategies & N & Mean & SD \\
\hline Memory Strategy & 52 & 3.36 & .51 \\
Cognitive Strategy & 52 & 3.26 & .34 \\
Compensation & 52 & 3.75 & .65 \\
Strategy & & & \\
Metacognitive & 52 & 3.40 & .51 \\
Strategy & & 3.27 & .56 \\
Affective Strategy & 52 & 3.37 & .64 \\
Social Strategy & 52 & & \\
\hline
\end{tabular}

However, in the Table 3, the order of frequent strategies employed by male and female student was different. Proficient male student used compensation strategies $(\mathrm{M}=3.60)$ followed by memory strategies $(M=3.32)$, metacognitive strategies $(M=3.31)$, social strategies $(M=3.31)$, cognitive strategies $(M=3.17)$, and affective strategies $(M=3 \cdot 10)$. Meanwhile, proficient female students used compensation strategies $(\mathrm{M}=3.84)$ followed by metacognitive strategies $(M=3.46)$, social strategies $(M=3.41)$, affective strategies $(M=3.40)$, memory strategies $(M=3.39)$, and cognitive strategies $(\mathrm{M}=3 \cdot 31)$.

Table 3. The Difference of writing strategies used by male and female students

\begin{tabular}{llllll}
\hline $\begin{array}{l}\text { Strategy } \\
\text { Categories }\end{array}$ & Gender & $\mathbf{N}$ & Mean & SD & $\begin{array}{c}\text { Sig. (2- } \\
\text { tailed) }\end{array}$ \\
\hline Memory & Male & 21 & 3.32 & .475 & $\mathrm{p}>.654$ \\
\cline { 2 - 7 } & Female & 31 & 3.39 & .539 & \\
\hline Cognitive & Male & $\mathbf{2 1}$ & 3.17 & .302 & $\mathrm{p}>.139$ \\
\cline { 2 - 7 } & Female & 31 & 3.31 & .349 & \\
\hline Compensation & Male & $\mathbf{2 1}$ & 3.60 & .642 & $\mathrm{p}>.190$ \\
\cline { 2 - 7 } & Female & 31 & 3.84 & .641 & \\
\hline Metacognitive & Male & $\mathbf{2 1}$ & 3.31 & .427 & $\mathrm{p}>.285$ \\
\cline { 2 - 7 } & Female & 31 & 3.46 & .554 & \\
\hline Affective & Male & $\mathbf{2 1}$ & 3.10 & .502 & $\mathrm{p}>.055$ \\
\cline { 2 - 7 } & Female & 31 & 3.40 & .567 & $\mathrm{p}>578$ \\
\hline Social & Male & $\mathbf{2 1}$ & 3.31 & .480 & \\
\cline { 2 - 6 } & Female & 31 & 3.41 & .732 & \\
\hline
\end{tabular}


This finding is different with Maharani et al (2018) in some points like their study found that male students mostly used memory strategies while female students mostly used metacognitive strategies. Indeed, their finding showed that compensation strategies was the lowest frequent strategies used by male students. However, this present study is in line with them in the part of cognitive strategies became the least strategies used by female students. This differences may occur because of the way of comparison. Maharani et al (2018) compared writing strategies of male and female students without considering their level of proficiency in writing while in this study, the rule was used by writer to see how proficient male and female are differences in employing writing strategies.

Moreover, this finding also found the female students more often used strategies that male students. It appears in the mean score of tables above where the female mean score higher than the male mean score in all strategies. This in support the previous studies of Umamah \& Hidayanti (2017) and Maharani et al (2018). Then, the sig. (2-tailed) above shows that all values are greater than .05. It concluded that the difference in the use of all strategies of males and female was not significant. This implies that the use of memory, cognitive, compensation, metacognitive, affective, and social strategies are not significant indicator of the difference in strategy used between proficient males and females in writing.

The writing strategies used by less proficient writers of male and female students

Table 4 shows that less proficient writers also uses compensation strategy $(M=3.57)$ as the most strategy used in writing and affective strategies $(\mathrm{M}=3.14)$ become the less frequent used. This finding is in line with the study conducted by Maharani et al (2018). As Sarab \& Farhani (2014) stated that compensation strategies compensate for deficient in the writer's limited knowledge base. In this case, less proficient also used compensation strategies to overcoming their limitation in writing since learning 


\section{JLIC}

L2 is not easy especially in writing skills which required many aspects to conduct good composition.

Table 4. The writing strategies used by less proficient writers

\begin{tabular}{lccc}
\hline Writing Strategies & N & Mean & SD \\
\hline Memory Strategy & 48 & 3.34 & .66 \\
Cognitive Strategy & 48 & 3.21 & .44 \\
Compensation & 48 & 3.57 & .62 \\
Strategy & & & \\
Metacognitive & 48 & 3.20 & .44 \\
Strategy & & & .63 \\
Affective Strategy & 48 & 3.14 & .73 \\
Social Strategy & 48 & 3.31 & \\
\hline
\end{tabular}

As table 5 shows that male students used compensation strategies $(M=3.64)$ followed by memory strategies $(M=3.38)$, social strategies $(M=3.29)$, cognitive strategies $(M=3.19)$, metacognitive strategies $(M=3.12)$, and affective strategies $(M=2.69)$. Meanwhile, female students used compensation strategies $(M=3.55)$ followed by memory strategies $(M=3.35)$, social strategies $(M=3.32)$, affective strategies $(M=3.29)$, metacognitive strategies $(M=3.23)$, and cognitive strategies $(\mathrm{M}=3.21)$.

Table 5. The Difference of writing strategies used by male and female students

\begin{tabular}{|c|c|c|c|c|c|}
\hline $\begin{array}{l}\text { Strategy } \\
\text { Categories }\end{array}$ & Gender & $\mathbf{N}$ & Mean & SD & $\begin{array}{l}\text { Sig. (2- } \\
\text { tailed) }\end{array}$ \\
\hline \multirow[t]{2}{*}{ Memory } & Male & 12 & 3.38 & .517 & \multirow{2}{*}{$\mathrm{p}>.925$} \\
\hline & Female & 36 & 3.35 & .703 & \\
\hline \multirow[t]{2}{*}{ Cognitive } & Male & 12 & 3.19 & .417 & \multirow{2}{*}{$\mathrm{p}>.897$} \\
\hline & Female & 36 & 3.21 & .454 & \\
\hline \multirow[t]{2}{*}{ Compensation } & Male & 12 & 3.64 & .581 & \multirow{2}{*}{$\mathrm{p}>.675$} \\
\hline & Female & 36 & 3.55 & .638 & \\
\hline \multirow[t]{2}{*}{ Metacognitive } & Male & 12 & 3.12 & .447 & \multirow{2}{*}{$\mathrm{p}>.468$} \\
\hline & Female & 36 & 3.23 & .437 & \\
\hline \multirow[t]{2}{*}{ Affective } & Male & 12 & 2.69 & .443 & \multirow{2}{*}{$\mathrm{p}<.004$} \\
\hline & Female & 36 & 3.29 & .617 & \\
\hline \multirow[t]{2}{*}{ Social } & Male & 12 & 3.29 & .722 & \multirow[b]{2}{*}{$\mathrm{p}>.910$} \\
\hline & Female & 36 & 3.32 & .738 & \\
\hline
\end{tabular}


This finding showed that less proficient male and female students used memory strategies as well as social strategies as the next top strategies used after compensation strategies. The difference occurred in the last strategies used where male had affective strategies $(\mathrm{M}=2.69)$ and female had cognitive strategies $(M=3.21)$. Affective strategies techniques helping learners to better handle their emotions, attitude, and motivation in their writing tasks (Sarab \& Farsani, 2014). They help learners to deal with their own emotions, motivation, and attitudes, such as lowering anxiety, self-rewards, self-encouragement. (Hong Shi, 2017) Meanwhile, cognitive strategies enable the learners to manipulate the language material in direct ways such as through reasoning, analysis, notetaking and so on (Oxford, 2003).

As shown in Table 5 , less proficient female students are not dominate the use of all strategies. Memory and compensation strategies are more used by male than female. Although the rest are dominated by less proficient female students. Moreover, memory, cognitive, compensation, metacognitive, and social strategies has sig.(2-tailed) greater than .05 ( $\mathrm{p}>.05)$. This indicates that the strategies do not have any differences between male and female student. On the other hand, affective strategies has sig. (2-tailed) lower than .05 $(\mathrm{p}<.05)$. It means that the difference in the use of the affective strategies of less proficient male and female student was significant. This finding indicates the fact that female $(\mathrm{M}=3.29)$, on average, employed more effective strategies than male $(M=2.69)$ was significant.

\section{CONCLUSION}

This study presents that writing strategies were employed differently by undergraduate students based on their proficiency and gender. The findings in this study found differently in some views of previous studies across their gender. They may occur due to the existence of gender itself is not a stable factor and there are several other factors influence the differences of writing strategies like students' proficiency, motivation, ethnic and so on. Moreover, 


\section{JLIC}

the study revealed that although proficient and less proficient students employed compensation strategies as the most frequently used, the proficient one knew more about how to generate ideas, when to plan, when to revise, when to ask, and understand the nature of writing. Proficient female students used more strategies in writing than less proficient female student while less proficient male students used more strategies in some kind of writing strategies than proficient male students. Finally, the finding in this study also contribute to the implication of teaching writing especially in instruction area which teacher can make students aware of the effectiveness of appropriate writing strategies in producing a good quality of writing.

\section{REFERENCES}

Arifin, S. (2017). L2 writing strategies used by EFL graduate students. Journal of ELT Research, 2(2), 115-129.

Aslan, O. (2009). The role of gender and language learning strategies in learning English. Thesis: Middle East Technical University.

Chen, Y. (2011). Study of the writing strategies used by Chinese nonEnglish majors", Theory and Practice in Language Studies, 1(3), 245-251.

Hidayati, K.H. (2018). Teaching writing to EFL learners: an investigation of challenges confronted by Indonesian teachers. LANGKAWI: Journal of the Association for Arabic and English, 4(1), 21-31.

Lea, M.R. \& Stierer, B. (Eds). 200o. Student Writing in Higher Education: New Context. Milton Keynes,USA: Open University Press.

Maarof, N. \& Murat, M. (2013). Writing strategies used by ESL upper secondary school student. International Education Studies, 6(4).

Maharani, S., Fauziati, E., \& Supriadi, S. (2018). An investigation of writing strategies used by the students on the perspective language proficiency and gender. International Journal of Multicultural and Multireligious Understanding, 5(5), 185-190.

Mohite, M. 2014. An Investigation into the English Language Writing Strategies Used by Polish EFL Secondary School Learners. Unpublished Dissertation: London Metropolitan University. 
$\mathrm{Mu}, \mathrm{C} \&$ Carrington, S. 2007. An Investigation of Three Chinese Students' English Writing Strategies, TESL-EJ, 11(1), 1-23.

Oxford, R.L. (2003). Language learning styles and strategies: an overview. GALA, 1-24.

Peñuelas, A.B.C. 2012. The writing strategies of American university students: focusing on memory, compensation, social and affective Strategies. ELIA 12, 77-113.

Qamariah, H. (2016). Teaching writing to EFL university students: some important issues (reducing writer's block and breakthrough to better teaching). GEEJ: Getsempena English Education Journal, 3(2), 23-31.

Sarab, M.R.A. \& Farsani, M.A. (2014). The relationship between writing strategies and personality types of graduate Iranian EFL learners. Applied Research on English Language, 3 (2), 69-83.

Shi H. (2017). Learning strategies and classification in education. Institute for Learning Styles Journal, 1, 24-36.

Silva, T. (1993). Toward an understanding of the distinct nature of L2 writing: The ESL research and its implications. TESOL Quarterly, 27 (4).

Umamah, A. \& Hidayanti, I. (2018). Writing strategies and factors contributing to EFL university students' preference. ELTEcho, 3(1), 70-76.

Wang, W., \& Wen, Q. (2002). L1 use in L2 composing process: an explotary study of 16 Chinese EFL writers. Journal of Second language Writing, 11(3), 225-246.

Winarto, A.E. 2002. Writing strategies employed by S1-students in developing a topic into an essay. Unpublished Thesis: State University of Malang. 